\title{
DOES CARBON PREFER FLAT OR CURVED SURFACES?
}

\author{
A. BURIAN ${ }^{a}$ AND J.C. DoRE ${ }^{b}$ \\ ${ }^{a}$ Institute of Physics, University of Silesia, Uniwersytecka 4, 40-007 Katowice, Poland \\ and \\ Centre of Polymer Chemistry, Polish Academy of Sciences \\ M. Skłodowskiej-Curie, 41-819 Zabrze, Poland \\ ${ }^{b}$ School of Physical Science, University of Kent, Canterbury CT2 7NR, U.K.
}

The presence of fullerene- and nanotube-like elements in carbons prepared from saccharose and anthracene by slow pyrolysis and then heat treated at $1000^{\circ} \mathrm{C}, 1900^{\circ} \mathrm{C}$, and $2300^{\circ} \mathrm{C}$ has been revealed using Raman spectroscopy. High energy X-ray diffraction has been used to examine the effect on these carbons of heat treatment. Tendency to graphitization of the anthracene-based carbon and resistance to graphitization of the saccharose carbon will be considered in the light of the formation of curved graphitic networks and cages. The obtained results lead us to propose a model of the structure of non-graphitizing and graphitizing carbons.

PACS numbers: $61.10 .-\mathrm{i}, 61.48 .+\mathrm{c}, 78.30 . \mathrm{Na}$

\section{Introduction}

About fifty years ago Rosalind Franklin [1] has found a clear distinction between disordered carbons which can be transformed into graphite upon high temperature annealing and those which cannot or can only with difficulty. These carbons are usually produced by controlled pyrolysis of a wide variety of organic precursors ranging from polymers to olive stones. Non-graphitizing carbons exhibit high porosity and hardness. Their internal surface area can be enhanced by activation, i.e. mild oxidation with carbon dioxide or steam. The resulting structures contain many micro-, meso- and macro-pores which make them useful for a wide range of commercial applications. Graphitizing carbons are soft, less porous and can be easily converted into graphite under thermal treatment. Despite many years of studies the question, why certain carbons are graphitizing and others are not, remains unanswered. In the model proposed by Franklin the basic building blocks are domains consisting of a few graphitic layers which are joined together by cross-links. However, the structure of these cross-links is not specified. It has been assumed that crystallite growth in these materials results from rearrangement of 
the whole domains. In graphitizing carbons the building blocks are approximately parallel to each other, exhibit a high degree of microtexture and weak cross-linking $[2,3]$. Therefore their arrangement can be easily transformed into a system, in which all layers are parallel. On the other hand, in non-graphitizing carbons, the strong cross-linking and random orientation of the basic structural blocks prevent the movement of the whole blocks and the material remains disordered, even at higher temperatures. The presence of $s p^{3}$ bonded atoms in non-graphitizing carbons has been practically ruled out as inconsistent with experimental data [4-6], and see the review paper by Harris [7].

The discoveries of fullerenes in 1985 [8] and carbon nanotubes in 1991 [9] have prompted several authors to consider the occurrence of non-six membered rings (e.g. pentagons or heptagons) in disordered carbons [7, 10-15]. It is noteworthy that the formation of curved graphitic network during carbon nucleation has been earlier recognised by Kroto and McKay [16]. In order to answer the title question we have chosen the carbon materials produced from saccharose and anthracene as two extreme examples of non-graphitizing and graphitizing carbons, respectively. Those samples offer the possibility of observation of a system, in which curved fragments are expected besides the graphite-like layers. The evolution of the structure has been examined by X-ray diffraction and curved surface fragments have been detected by the use of the Raman spectroscopy method.

\section{Experiment}

The preparation of the carbon materials by the pyrolysis of saccharose and anthracene and subsequent heat treatment was described in our previous paper [17]. The X-ray diffraction intensities were collected on the ID15A high energy beam line at ESRF (Grenoble) in the range of the scattering vector $K=4 \pi \sin \theta / \lambda$ ( $2 \theta$ is the scattering angle and $\lambda$ is the wavelength of the incident radiation) extended up to $26 \AA^{-1}$. The samples were mounted in a $3 \mathrm{~mm}$ diameter thin walled Lindemann glass capillary and then installed on the diffractometer axis. The intensity from the empty capillary was also measured and used to correct the raw data for the capillary scattering. Then the data were corrected for polarisation (the incident beam is polarised to about $95 \%$ ), absorption and Compton scattering. In a high $K$-range square of the atomic scattering factor approaches zero and the whole measured intensity is due to incoherent scattering. Therefore the tabulated values of the Compton intensity can be used for normalisation of the corrected data. Raman spectra were recorded at ambient conditions in a back-scattering geometry using a Raman microspectrometer and an argon laser as the excitation source. The $457.2 \mathrm{~nm}, 476.5 \mathrm{~nm}, 488.0 \mathrm{~nm}$, and $514.3 \mathrm{~nm}$ laser excitation wavelengths were used in the present work. The Raman measurements were described in detail in our previous paper [17].

\section{Scattering formalism}

For disordered and polycrystalline materials the diffraction pattern arises from the coherent interference of scattered waves from distributed atoms as scat- 
tering centres. In the case of identical atoms and powdered samples the structure factor $S(K)$ per atom averaged over all orientations can be written as

$$
S(K)=\frac{I(K)}{f^{2}}=\frac{1}{N} \sum_{i=1}^{N} \sum_{j=1}^{N} \frac{\sin \left(K r_{i j}\right)}{K r_{i j}}
$$

where $I(K)$ is the coherent intensity, $f(K)$ is the atomic scattering factor for carbon and $r_{i j}$ denotes the distance between $i$-th and $j$-th atom. The scattering data can be converted to real space by the inverse Fourier transform yielding the reduced radial distribution function (RRDF)

$$
4 \pi r\left[\rho(r)-\rho_{0}\right]=\frac{2}{\pi} \int_{0}^{K_{\max }} K[S(K)-1] W(K) \sin (K r) \mathrm{d} K,
$$

where $\rho_{0}$ is the number density and $W(K)$ is the window function. In the present work $W(K)=\sin \left(\pi K / K_{\max }\right) /\left(\pi K / K_{\max }\right)$ was taken for computations.

\section{Data interpretation}

\subsection{X-ray scattering}

The scattering factors, calculated according to Eq. (1), are shown in Figs. 1 and 2 together with the graphite data for comparison. Beyond the $22 \AA^{-1}$ limit $S(K)$ consists mainly of high frequency noises and this value was taken for computations as $K_{\max }$. In the $16-22 \AA^{-1}$ region all the $S(K)$ data sets oscillate around the unity line which indicates that there are no significant normalisation problems. For both carbons annealed at $1000^{\circ} \mathrm{C}$, the diffraction patterns are characteristic of the short range features in the disordered turbostratic carbon, in which graphene sheets are stacked without spatial correlations [18]. All diffraction peaks are of the (002) and $(h k 0)$ type [19]. The first diffraction peak for the anthracene carbon, appearing at $1.813 \AA^{-1}$, is higher than that of the saccharose carbon, observed at $1.675 \AA^{-1}$, which suggests that in the anthracene sample the number of the graphene layers is greater when compared with the saccharose one. A close examination of the first peak position for the saccharose-based carbon leads to the conclusion that it is shifted towards a smaller $K$ value considered in relation to graphite. The values of the first peak position $\left(K_{1}\right)$ and the interplanar spacing $\left(d_{h k l}\right)$, estimated using the Bragg equation, are listed in the Table. The value $3.75 \AA$, obtained for the saccharose carbon is significantly greater than that of graphite (the (002) peak position is $1.875 \AA^{-1}$ and the resulting value of the interplanar spacing is $3.35 \AA$ ). However, it should be remembered that the Bragg equation is not strictly applicable for the case of small and disordered crystallites and the position of the very broad first peak can be determined only with low precision. At higher temperatures the interplanar spacings are typical of the turbostratic carbons. For the anthracene carbon at $1000^{\circ} \mathrm{C} d$ is in the range characteristic of the turbostratic carbon and at higher temperatures approaches the value found for graphite. Comparison of the whole diffraction patterns of the investigated carbons and graphite clearly shows that the anthracene carbon transforms into graphite upon high temperature heat treatment while the saccharose carbon remains highly disordered, even at $2300^{\circ} \mathrm{C}$. An analysis of the experimental data 


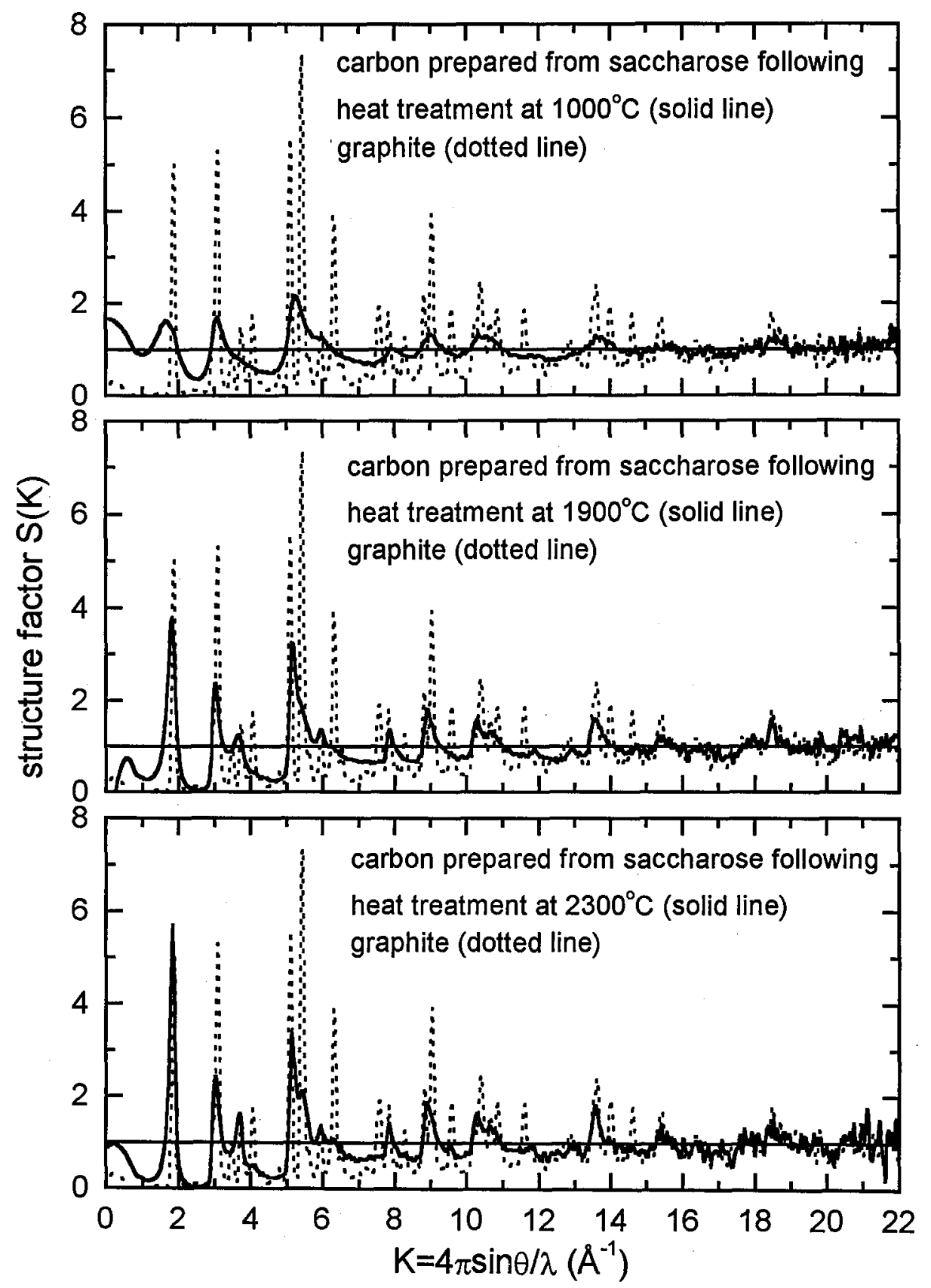

Fig. 1. The structure factor $S(K)$ for carbons prepared from saccharose following heat treatment at $1000^{\circ} \mathrm{C}, 1900^{\circ} \mathrm{C}$, and $2300^{\circ} \mathrm{C}$ compared with that of graphite. 

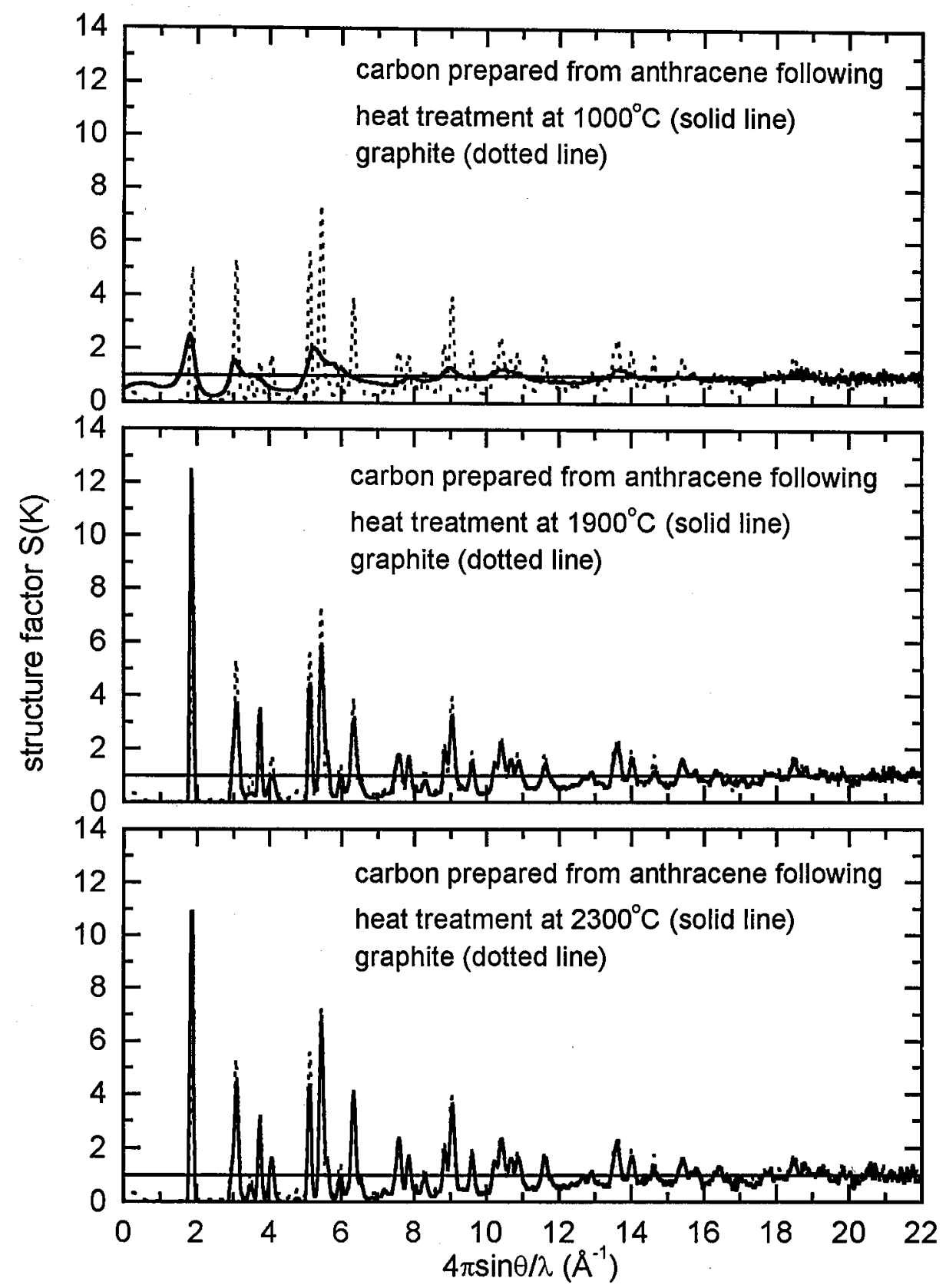

Fig. 2. The structure factor $S(K)$ for carbons prepared from anthracene following heat treatment at $1000^{\circ} \mathrm{C}, 1900^{\circ} \mathrm{C}$, and $2300^{\circ} \mathrm{C}$ compared with that of graphite. 


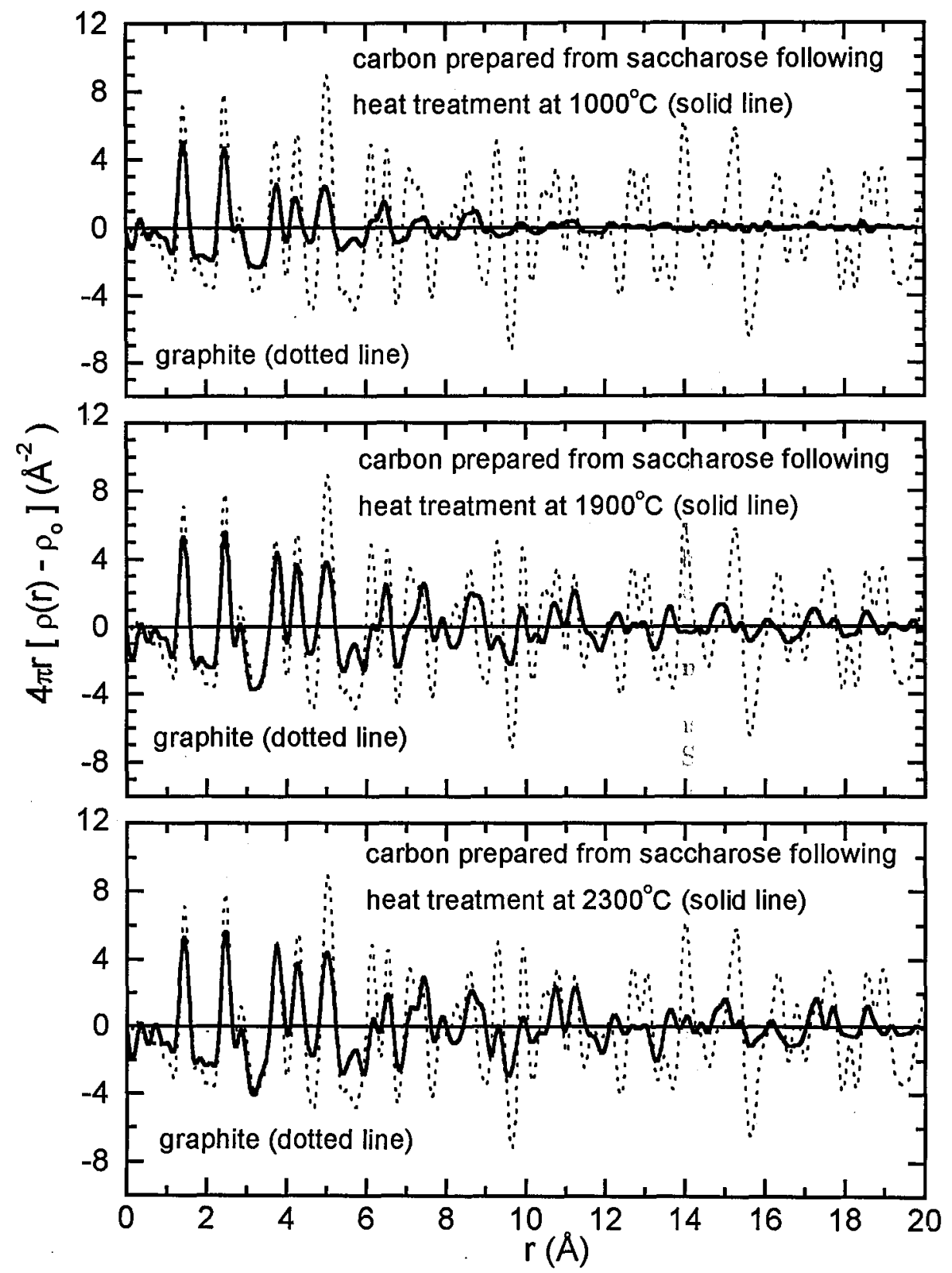

Fig. 3. The reduced radial distribution function $4 \pi r\left[\rho(r)-\rho_{0}\right]$ for carbons prepared from saccharose following heat treatment at $1000^{\circ} \mathrm{C}, 1900^{\circ} \mathrm{C}$, and $2300^{\circ} \mathrm{C}$ compared with that of graphite. 

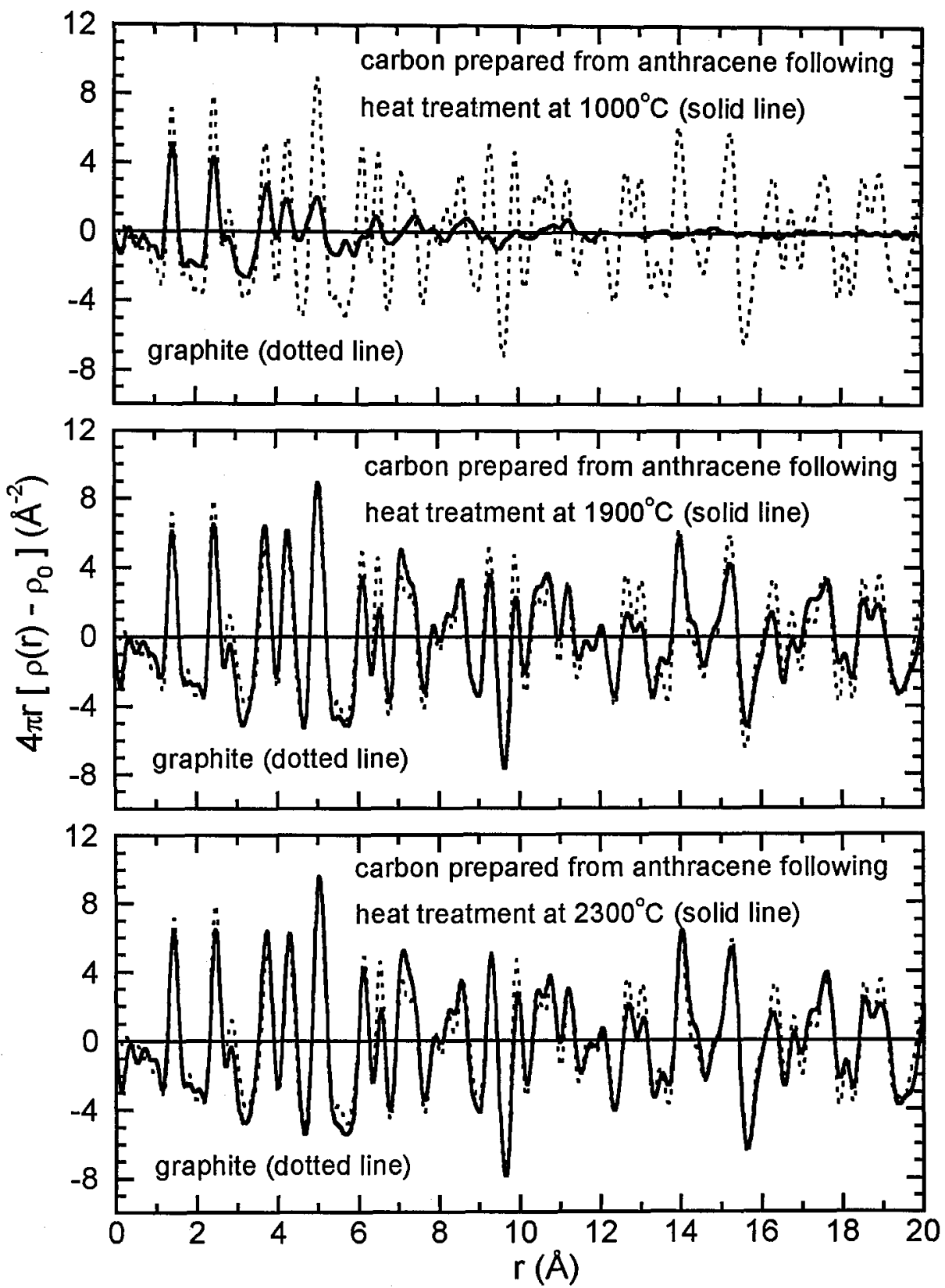

Fig. 4. The reduced radial distribution function $4 \pi r\left[\rho(r)-\rho_{0}\right]$ for carbons prepared from anthracene following heat treatment at $1000^{\circ} \mathrm{C}, 1900^{\circ} \mathrm{C}$, and $2300^{\circ} \mathrm{C}$ compared with that of graphite. 
TABLE

The first peak positions and the interplanar spacings for the saccharoseand anthracene-based carbons following heat treatment at $1000^{\circ} \mathrm{C}$, $1900^{\circ} \mathrm{C}$, and $2300^{\circ} \mathrm{C}$.

\begin{tabular}{c|c|c|c|c}
\hline \hline \multirow{2}{*}{$\begin{array}{c}\text { Heating } \\
\text { temperature }\end{array}$} & \multicolumn{2}{|c|}{$\begin{array}{c}\text { Saccharose-based } \\
\text { carbon }\end{array}$} & \multicolumn{2}{c}{$\begin{array}{c}\text { Anthracene-based } \\
\text { carbon }\end{array}$} \\
\cline { 2 - 5 } & $\begin{array}{c}\text { First peak } \\
\text { position }\end{array}$ & $\begin{array}{c}\text { Interplanar } \\
\text { spacing }\end{array}$ & $\begin{array}{c}\text { First peak } \\
\text { position }\end{array}$ & $\begin{array}{c}\text { interplanar } \\
\text { spacing }\end{array}$ \\
\hline $1000^{\circ} \mathrm{C}$ & $1.675 \AA^{-1}$ & $3.75 \AA$ & $1.813 \AA^{-1}$ & $3.47 \AA$ \\
$1900^{\circ} \mathrm{C}$ & $1.825 \AA^{-1}$ & $3.44 \AA$ & $1.863 \AA^{-1}$ & $3.37 \AA$ \\
$2300^{\circ} \mathrm{C}$ & $1.838 \AA^{-1}$ & $3.42 \AA$ & $1.863 \AA^{-1}$ & $3.37 \AA$
\end{tabular}

in a real space supports these conclusions. Different features in the RRDFs can be seen in Figs. 3 and 4 . The broad peaks at $1000^{\circ} \mathrm{C}$ are associated with the defective network with the extent of geometrical correlations up to about $12 \AA$. The broadening effect is more pronounced for $K>6 \AA^{-1}$ where the peaks are strongly attenuated in comparison with the sharp Bragg peaks, observed for graphite. Drastic changes between the two carbons are observed at $1900^{\circ} \mathrm{C}$ and $2300^{\circ} \mathrm{C}$. For the anthracene-based carbon, all the RRDF graphite peaks are reproduced, however some peaks have slightly lower amplitudes. Quite different features are observed for the saccharose-based carbon. Although the RRDFs at $1900^{\circ} \mathrm{C}$ and $2300^{\circ} \mathrm{C}$ exhibit a structure to about $20 \AA$, the peaks have generally lower amplitudes compared with graphite and not all graphite peaks are reproduced in the diffraction pattern of the saccharose carbon. This result clearly indicates that carbon does not convert into graphite, even at so high temperatures, and remains highly disordered. Now the question arises: why is the anthracene carbon graphitizing and the saccharose carbon is not? In the next section we will try to explain different behaviour of the carbons upon annealing using the Raman spectroscopy technique.

\subsection{Raman spectroscopy}

In order to address the above question we have applied the Raman scattering method in a low frequency range using the laser wavelength of $488.0 \mathrm{~nm}$. A single-crystal graphite exhibits the $D_{6 h}^{4}$ symmetry and the zone-centre modes can be decomposed into the following irreducible representation: $\Gamma=A_{2 \mathrm{u}}+2 B_{2 \mathrm{~g}}+$ $E_{1 \mathrm{u}}+2 E_{2 \mathrm{~g}}$ [20]. The $E_{2 \mathrm{~g}}$ modes are Raman active and appear at $1581 \mathrm{~cm}^{-1}$ and $17 \mathrm{~cm}^{-1}$. The low frequency mode is usually unobservable. The Raman data, recorded in the first- and second-order ranges, have been analysed in our previous paper [17]. Here we focus on a low frequency range which is silent for graphite or other diamond-like materials.

The features observed in this frequency range can be considered as good markers for specifying curved space geometry, related to fullerenes or carbon nanotubes. Those cannot be explained by the graphite structure. The sharp lines, seen in Figs. 5 and 6 at $464 \mathrm{~cm}^{-1}$ have been experimentally observed and theoretically 


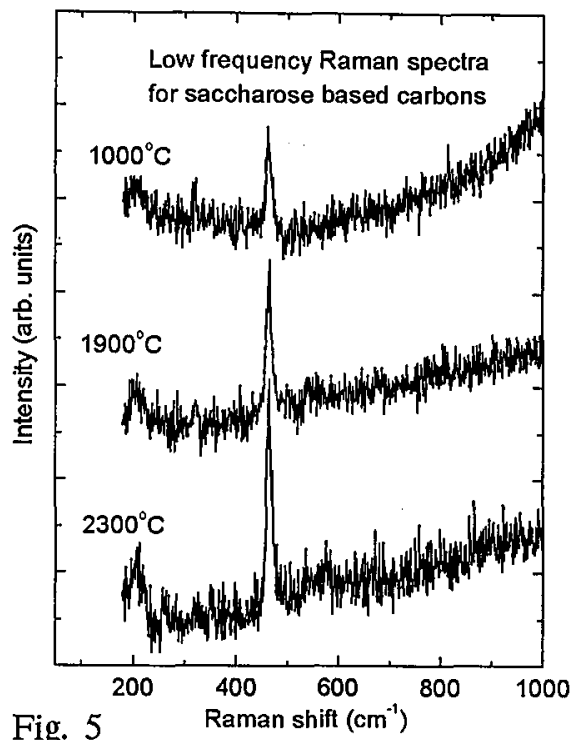

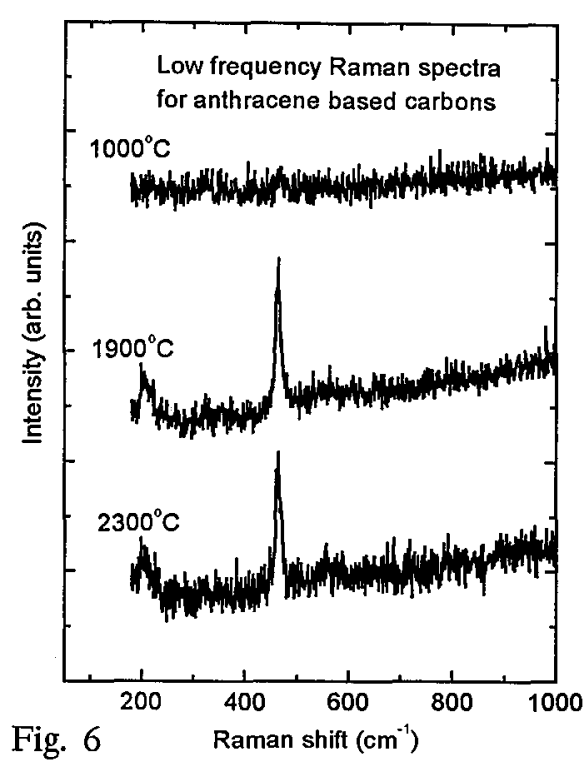

Fig. 5. The $180-1000 \mathrm{~cm}^{-1}$ Raman spectra of the saccharose-based carbons following heat treatment at $1000^{\circ} \mathrm{C}, 1900^{\circ} \mathrm{C}$, and $2300^{\circ} \mathrm{C}$.

Fig. 6. The 180-1000 $\mathrm{cm}^{-1}$ Raman spectra of the anthracene-based carbons following heat treatment at $1000^{\circ} \mathrm{C}, 1900^{\circ} \mathrm{C}$, and $2300^{\circ} \mathrm{C}$.

established for the $\mathrm{C}_{70}$ fullerene [21, 22]. In Ref. [21] the high quality Raman spectra, obtained for the pure $\mathrm{C}_{70}$ samples, are shown. The peak at about $460 \mathrm{~cm}^{-1}$ has clearly the strongest intensity and remaining peaks have evidently lower intensities. It is essential to point out that this line appears for the saccharose carbon annealed at $1000^{\circ} \mathrm{C}, 1900^{\circ} \mathrm{C}$, and $2300^{\circ} \mathrm{C}$ whereas for the anthracene carbon only at $1900^{\circ} \mathrm{C}$ and $2300^{\circ} \mathrm{C}$. Moreover its intensity increases with heating temperature for the former and has lower intensity, which is practically temperature independent for the latter. We explain this feature by the formation of curved surfaces with a symmetry of $\mathrm{C}_{70}$ or higher fullerenes. The main difference between the investigated carbons is that the fullerene line is observed at $1000^{\circ} \mathrm{C}$ for the saccharose carbon and is not for the carbon prepared from anthracene. Therefore one can conclude that in the case of the non-graphitizing carbon such a preparation procedure and subsequent heat treatment at $1000^{\circ} \mathrm{C}$ can result in the formation of elements which are fullerene-like in the structure. At higher annealing temperatures this tendency is more evident. It is important to emphasise that we do not suggest the formation of complete fullerenes. Only fragments of them, containing five-membered rings, are expected to occur in the investigated samples. This suggestion can explain the presence of only the most intense line in the recorded Raman spectra. The curved elements may occur between graphene-like regions in the investigated materials, which have been suggested in Ref. [1] and named cross-links. The absence of the $464 \mathrm{~cm}^{-1}$ line for the anthracene carbon at $1000^{\circ} \mathrm{C}$ indicates that fullerene-like fragments are not formed. These conclusions are sup- 
ported by previously reported high-resolution electron microscopy studies, which also have provided evidence for the presence of curved surface elements [15] in the non-graphitizing carbon and their absence in the graphitizing carbon at early stage of heat treatment. When the annealing temperature increases, the $464 \mathrm{~cm}^{-1}$ line appears for the anthracene-based carbon but a proportion of fullerene-like fragments is apparently lower. All the Raman spectra shown in the present paper are expressed in the same scale and in the presented figures are shifted for clarity. Therefore comparison of them can directly be made in relation to the background line.

The features observed below $250 \mathrm{~cm}^{-1}$ for both carbons at $2300^{\circ} \mathrm{C}$, shown in Figs. 7 and 8, cannot be interpreted as the fullerene intramolecular modes [22]. The peaks at about $200 \mathrm{~cm}^{-1}$, at about $145 \mathrm{~cm}^{-1}$ for both carbons at the excitation wavelength of $457.2 \mathrm{~nm}$ and in the range of $75-100 \mathrm{~cm}^{-1}$ are related to the $A_{1 \mathrm{~g}}$ radial breathing mode, observed for carbon nanotubes [22, 23]. It has been found that the frequency of this mode depends on the diameter of the nanotube [23-25]. In order to test the validity of this suggestion we performed the additional Raman experiment using the $457.2 \mathrm{~nm}, 476.5 \mathrm{~nm}, 488.0 \mathrm{~nm}$, and $514.3 \mathrm{~nm}$ laser excitation wavelengths. It is known that for nanotubes of the diameter as small as $2 \mathrm{~nm}$ the quantum size effect plays a role and shifts of the lines with the excitation wavelength due to resonant Raman scattering are expected. Such shifts can be seen

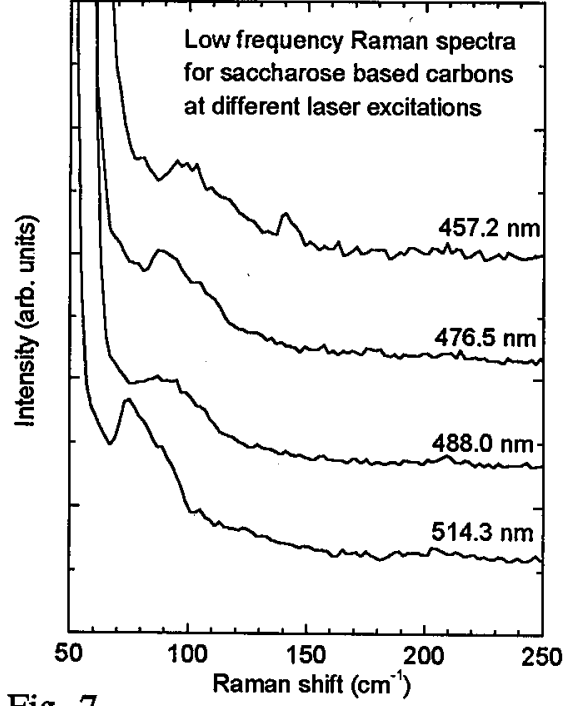

Fig. 7

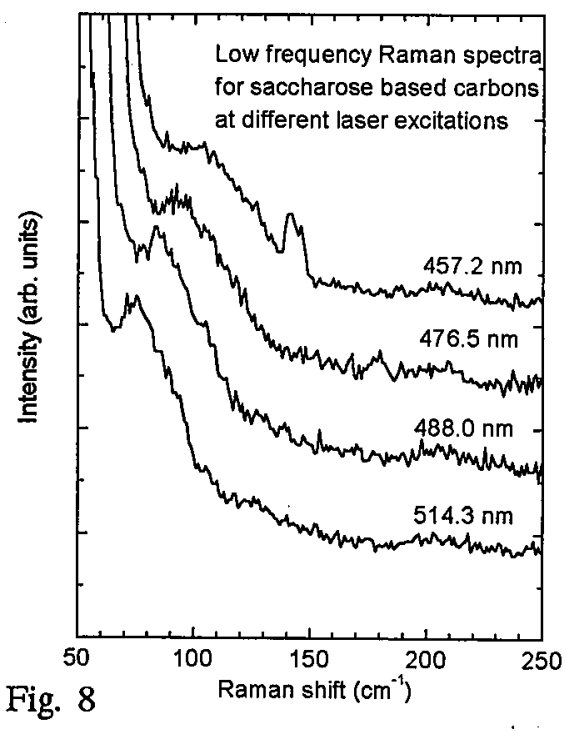

Fig. 8

Fig. 7. The $50-250 \mathrm{~cm}^{-1}$ Raman spectra of the saccharose-based carbons following heat treatment at $1000^{\circ} \mathrm{C}, 1900^{\circ} \mathrm{C}$, and $2300^{\circ} \mathrm{C}$ recorded with different excitation wavelengths.

Fig. 8. The 50-250 $\mathrm{cm}^{-1}$ Raman spectra of the anthracene-based carbons following heat treatment at $1000^{\circ} \mathrm{C}, 1900^{\circ} \mathrm{C}$, and $2300^{\circ} \mathrm{C}$ recorded with different excitation wavelengths. 
in Figs. 7 and 8 . The estimated values of the nanotube diameter extend from $1 \mathrm{~nm}$ to about $2.2 \mathrm{~nm}$, according to the plots reported in Refs. [23-25]. This is the range for which the above-mentioned effects are expected to appear. Resonant Raman scattering occurs when the energy of excitation is close to the energy of strong optical absorption electronic transitions. Such transitions are possible between the well-localised electronic density of states peaks, which occur in nanotubes of small enough diameter. The similar experiments have been performed for pure nanotubes and it has been shown that the energy difference between the well-defined densities of states of carbon nanotubes is comparable with the excitation energies used of the measurements [23]. The samples heated at $2300^{\circ} \mathrm{C}$ were selected for the measurements because their electrical conductivity approaches the value typical of graphite and therefore the presence of localised states resulting from disorder is ruled out. From these findings we conclude that nanotube-like fragments are also formed in the investigated carbons.

\section{Conclusions}

The performed X-ray diffraction and Raman scattering experiments have prompted us to suggest that fullerene- and nanotube-like elements with curved structures may be present in the well-known forms of carbon as the saccharose- and anthracene-based carbons. Such elements occur together with graphitic layers and can be regarded as two possible ways of arrangement of the carbon atoms during the pyrolysis and heat treatment processes. The formation of the curved structures can explain resistance of the saccharose carbon to graphitization because fullereneand nanotube-like elements are stable. In the case of the anthracene carbon these elements are formed at higher temperatures and in much lower proportions and cannot prevent graphitization. We suggest that their formation occurs near edges of the growing graphite crystallites in the form of folded graphene sheets which can reduce significantly the surface energy. This suggestion is based on the previous finding that the folded graphene sheets may be formed in carbons expressed to extreme conditions [11]. In summary, to answer the title question, it should be stated that the different properties of the final materials after heat treatment depend on the concurrent processes relating to the formation of flat graphite-like regions and curved fullerene- or nanotube-like fragments.

\section{References}

[1] R.E. Franklin, Proc. R. Soc. A 209, 196 (1951).

[2] A. Oberlin, Carbon 22, 521 (1984).

[3] J.N. Rouzaud, A. Oberlin, Carbon 27, 517 (1989).

[4] W. Ruland, Chem. Phys. Carbon 4, 1 (1968).

[5] D.R. McKenzie, Rep. Prog. Phys. 59, 1611 (1996).

[6] J. Diaz, G. Paolicelli, S. Ferrer, F. Comin, Phys. Rev. B 54, 8054 (1996).

[7] P.J.F. Harris, Int. Mater. Rev. 42, 206 (1997). 
[8] H.W. Kroto, J.R. Meath, S.C. O'Brien, R.F. Smalley, Nature 381, 162 (1985).

[9] S. lijima, Nature 354, 56 (1991).

[10] P.R. Buseck, H. Bo-Jun, L.P. Keller, Energy Fuels 1, 105 (1987).

[11] D. Ugarte, Chem. Phys. Lett. 198, 596 (1992).

[12] S.J. Townsend, T.J. Lenosky, D.A. Muller, C.S. Nickols, W. Elser, Phys. Rev. Lett. 69, 921 (1992).

[13] H. Terrones, M. Terrones, W.K. Hsu, Chem. Soc. Rev. 24, 341 (1991).

[14] P.J.F. Harris, S.C. Tsang, Philos. Mag. A 76, 667 (1997).

[15] P.J.F. Harris, A. Burian, S. Duber, submitted to Philos. Mag. Lett.

[16] H.W. Kroto, K. McKay, Nature 331, 328 (1988).

[17] A. Burian, P. Daniel, S. Duber, J.C. Dore, submitted to Phys. Rev. B.

[18] B.E. Warren, P. Bodenstein, Acta Crystallogr. 20, 602 (1970).

[19] J.C. Dore, M. Śliwiński, A. Burian, W.S. Howells, D. Cazorla, J. Phys., Condens. Matter 11, 9189 (1999).

[20] K.K. Mani, R. Ramani, Phys. Status Solidi B 61, 659 (1974).

[21] B. Chase, N. Herron, E. Holler, J. Chem. Phys. 96, 4262 (1992).

[22] M.S. Dresselhaus, G. Dresselhaus, P.C. Eklund, Science of Fullerenes and Carbon Nanotubes, Academic Press, San Diego 1996.

[23] A.M. Rao, E. Richter, S. Bandow, B. Chase, P.C. Eklund, K.A. Williams, S. Fang, K.R. Subbaswamy, M. Meneo, A. Thess, R.E. Smalley, G. Dresselhaus, M.S. Dresselhaus, Science 275, 187 (1998).

[24] R. Saito, T. Takeya, T. Kimura, G. Dresselhaus, M.S. Dresselhaus, Phys. Rev. B 57, 4145 (1998).

[25] S. Bandow, A. Asaka, Y. Saito, A.M. Rao, L. Grigorian, E. Richter, P.C. Eklund, Phys. Rev. Lett. 80, 3779 (1998). 